\section{LINHAS DE FORÇA DE UM DISPOSITIVO: OS PROFESSORES DE EDUCAÇÃO FÍSICA INICIANTES E AS RELAÇÕES DE PODER NA ESCOLA}

\author{
FORCE LINES OF A DEVICE: BEGINNER PHYSICAL EDUCATION TEACHERS \\ AND POWER RELATIONS AT SCHOOL
}

\section{LIINEAS DE FUERZA DE UN DISPOSITIVO: LOS PROFESORES DE EDUCACIÓN FÍSICA PRINCIPIANTES Y LAS RELACIONES DE PODER EN LA ESCUELA}

\author{
Franciele Roos da Silva Ilha*, Álvaro Moreira Hypolito*
}

\begin{abstract}
Palavras chave:
Poder.

Educação Física.

Relações

interpessoais.

Resumo: Objetivou-se analisar as linhas de força do dispositivo da esportivização, traçadas a partir da captura das relações de poder entre professores de Educação Física iniciantes e outros sujeitos na escola. Esta investigação teve fundamentação teóricometodológica nos estudos de Foucault e Deleuze, com informações coletadas na rede municipal de ensino de Pelotas/RS, incluindo entrevistas com professores de Educação Física iniciantes na carreira docente e um estudo de caso em uma escola da rede. As linhas de força - ou a dimensão do poder do dispositivo - foram evidenciadas por meio do discurso da necessidade dos professores de Educação Física em atender aos interesses dos alunos por certas modalidades esportivas; pelas disputas entre professores de Educação Física de uma escola (iniciantes e experientes) e entre um professor de Educação Física iniciante e o diretor da escola sobre o espaço físico, bem como os embates suscitados pelo status da Educação Física e seus saberes.
\end{abstract}

Keywords

Power.

Physical education. Interpersonal relations.

Abstract: This article analyzed the force lines of the sportivization device traced from the capture of power relations between beginner Physical Education teachers and other subjects at school. This study had its theoretical-methodological foundation in the studies of Foucault and Deleuze, with information collected from municipal schools in Pelotas, Brazil, including interviews with beginner Physical Education teachers and a case study in a municipal school. The device's force lines or power dimension were evidenced by the discourse on teachers' need to serve students' interest in certain sports; by disputes among Physical Education teachers of a school - both beginners and experienced teachers - and between a beginner Physical Education teacher and the school principal about the physical space, as well as debates on the status of Physical Education and its knowledges.

Resumen: Se objetivó analizar las líneas de fuerza del dispositivo de la deportividad, trazadas a partir de la captura de las relaciones de poder entre profesores de educación física principiantes y otros sujetos en la escuela. Esta investigación tuvo fundamentación teórico-metodológica en los estudios de Foucault y Deleuze, con informaciones recolectadas en la red municipal de enseñanza de Pelotas (RS), incluyendo entrevistas con profesores de Educación Física principiantes en la carrera docente y un estudio de caso en una escuela de la red. Las líneas de fuerza o la dimensión del poder del dispositivo fueron evidenciadas por medio del discurso de la necesidad de los profesores de Educación Física en atender a los intereses de los alumnos por ciertas modalidades deportivas; por las disputas entre profesores de Educación Física de una escuela (principiantes y experimentados) y entre un profesor de Educación Física principiante y el director de la escuela sobre el espacio físico, así como los embates suscitados por el status de la Educación Física y sus saberes.
*Universidade Federal de Pelotas. Pelotas, RS, Brasil. E-mail: franciele.ilha@yahoo.com.br; alvarohypolito@gmail.com

Recebido em: 03-06-2017 Aprovado em: 30-10-2017

DOI: http://dx.doi.org/10.22456/1982-8918.73933 (c) (i) () Licence 


\section{INTRODUÇÃO}

A discussão das relações de poder de um dispositivo emergiu da investigação da regulação curricular da Educação Física e seus efeitos no trabalho de docentes iniciantes. A partir desta, foi possível identificar a recorrência de certas discursividades e visibilidades no corpus de pesquisa em relação a esta regulação, as quais articuladas formavam uma rede: 0 dispositivo, no sentido foucaultiano. Foucault (1992) explica que o dispositivo é um conjunto de elementos heterogêneos formado pelo dito e o não dito, uma rede que se estabelece com tais elementos.

Na medida em que a maioria das recorrências se relacionava com o esporte, elegeu-se este como o eixo analítico central para a construção de um dispositivo chamado esportivização da Educação Física (ILHA, 2015), pela emersão do esporte como um modo de regulação curricular deste componente na escola.

Ao tratar da regulação curricular da Educação Física pelo conceito de dispositivo, aqui nomeado como da esportivização da Educação Física, não se defende que o esporte de rendimento, com todas as implicações que advêm de sua prática (aspecto institucional, estrutural e organizacional, equipe de profissionais), consiga se efetivar nas aulas de Educação Física. Defende-se, por certo, que certas características do esporte de rendimento atravessam as práticas curriculares da Educação Física na escola, ao entrar nos jogos de poder-saber, que envolvem a escolha de conteúdos, metodologias, relação professor-alunos, professor-outros profissionais da escola, professor-pais.

Portanto, o termo Esportivização se traduz pela identificação de certas modalidades esportivas nas aulas de Educação Física e suas características (descritas anteriormente) são privilegiadas em comparação com outras, aproximando-se de princípios do esporte de rendimento.

Acerca do termo foucaultiano de dispositivo, Deleuze (1990) explica-o como um conceito complexo que envolve curvas de visibilidade - linhas de luz que constituem figuras variáveis (as práticas) e as curvas de enunciação formadas por enunciações (os discursos) que distribuem posições diferenciais dos seus elementos. Mas o dispositivo também é formado por linhas de força - dimensão do poder que atravessa todo o dispositivo - e linhas de objetivação, as quais propiciam o processo de subjetivação, a produção de si por si mesmo. Estas últimas predispõem as linhas de fuga, as quais escapam às forças e aos saberes de um dispositivo, e se movem para outro. Ao possibilitarem a passagem de um dispositivo a outro, permitem a emergência das linhas de ruptura, pois estão no limite do dispositivo.

Nos limites deste artigo, o foco recai nas linhas de força do dispositivo da esportivização, as quais permitem convergir 0 olhar para as relações de poder na configuração dos saberes. Essas linhas delineiam o caminho das curvas de visibilidade e dos regimes de enunciabilidade. As linhas de força, ao compor a dimensão do poder no dispositivo, estabelecem relações de força e sustentam tipos de saber: a produção de práticas e discursos de esportivização.

Práticas discursivas e não discursivas de esportivização da Educação Física, como saberes do dispositivo, não regulam o currículo dessa disciplina na escola sem escapar das lutas que envolvem o jogo curricular: o currículo é um território de confronto.

As relações de poder no espaço escolar não são resultado de forças superiores, que buscam o governo dos sujeitos e o cumprimento exímio de regras impostas, mesmo 
que algumas políticas educacionais possam ter essa pretensão. 0 exercício do poder prevê relações que se dão no próprio contexto, pois são as ações de uns sobre as ações de outros que contam neste jogo.

Com base em tais pressupostos, interroga-se: como as linhas de força têm delineado os discursos apresentados sobre o dispositivo da esportivização da Educação Física? Como as relações de poder se estabelecem entre o professor de Educação Física iniciante e o professor de Educação Física mais antigo; o professor de Educação Física iniciante e seus alunos; 0 professor de Educação Física iniciante e os membros da equipe diretiva?

Tais questões delineiam o objetivo do estudo: analisar as linhas de força do dispositivo da esportivização, traçadas a partir da captura das relações de poder de professores de Educação Física iniciantes com outros sujeitos na escola. A fundamentação teórico-metodológica teve como base os estudos de Michel Foucault e Gilles Deleuze.

A relevância do estudo pode ser apontada pela escassa produção no campo temático que trata do trabalho de docentes iniciantes na Educação Física Escolar, tema ainda tímido no meio acadêmico e científico, conforme levantamento realizado por llha (2015). Além disso, considera-se importante investigar como um modo de regulação das práticas curriculares da Educação Física na escola, neste caso, o dispositivo da esportivização, promove relações de força/poder entre os sujeitos da escola. Tais questões repercutem na construção curricular da disciplina e sobre o trabalho dos docentes iniciantes e não iniciantes.

\section{METODOLOGIA}

Nesta pesquisa, que é de caráter qualitativo, se realizou uma pesquisa de campo na rede municipal de ensino de Pelotas/RS. Inicialmente realizaram-se seis entrevistas semiestruturadas com professores de Educação Física iniciantes na carreira docente na escola básica. Posteriormente, foi feito o estudo de caso em uma escola, na qual um desses professores foi entrevistado.

Na sequência da pesquisa, foram feitas observações de aulas de Educação Física na escola selecionada para a realização do estudo de caso, com anotações em um diário de campo. Também foi feita uma entrevista com a coordenadora das áreas desta escola.

Os critérios de escolha dos professores foram os seguintes: todos os professores de Educação Física iniciantes (com até cinco anos de carreira docente) da rede municipal de ensino de Pelotas que atuassem no ensino fundamental e na zona urbana e que aceitassem participar da pesquisa. $O$ número reduzido de professores enquadrados nestes critérios pode ser explicado pela exoneração de muitos docentes, conforme salientou a responsável pela área de Educação Física na rede municipal. Contudo, ela não tinha dados precisos para ilustrar tal informação.

Com a autorização de cada professor, as entrevistas foram gravadas em áudio para que detalhes dos discursos não fossem perdidos, tendo sido necessária a respectiva aceitação para a efetivação das entrevistas, a partir da assinatura do Termo de Consentimento Livre e Esclarecido. Os nomes dos professores utilizados na análise são fictícios, preservando suas identidades. Os procedimentos utilizados respeitam as normas internacionais de experimentação com humanos, conforme Resolução n.466, de 12 de dezembro de 2012 (BRASIL, 2012). 
Em relação ao período de realização das observações, a intenção foi realizá-las durante dois meses, o que ocorreu no início em outubro de 2013, prolongando-se até o final do ano letivo das escolas municipais de Pelotas (dezembro de 2013). As observações ocorreram de duas a três vezes por semana, no tempo de cada aula, que é de 40 minutos.

As entrevistas e o diário de campo foram analisados na sua discursividade. Silveira (2007), a fazer menção à análise discursiva de entrevistas, contribui para a analítica do corpus da pesquisa. Ela sugere olhá-las como eventos discursivos complexos, considerando os jogos de linguagem, a reciprocidade, a intimidade, o poder e as redes de representação.

\section{RESULTADOS E DISCUSSÃO}

Algumas abordagens de ensino ou teorias curriculares no campo da Educação Física são associadas à ideia da esportivização, como aquelas que se preocupam demasiadamente com a técnica e a tática esportiva, incentivam a competição dos alunos, buscam melhorias em suas performances esportivas, promovem a exclusão dos alunos menos habilidosos, bem como preconizam o cumprimento de regras oficiais das modalidades esportivas nas aulas de Educação Física Escolar. Tais aspectos recaem na caracterização de objetivos e metas do esporte de rendimento.

Dentre as perspectivas curriculares de ensino da Educação Física, a chamada esportivização aproxima-se da abordagem denominada esportivismo, a qual se caracteriza por uma perspectiva não crítica de currículo. Como exemplos de currículos tradicionais ou não críticos, Neira e Nunes (2009) nomeiam os currículos esportivo, globalizante, desenvolvimentista e saudável, já que através deles objetiva-se ensinar o passe no futebol, o desenvolvimento do esquema corporal, o cálculo do Índice de Massa Corporal, mas não se ensina o porquê destes conhecimentos comporem o currículo, sua trajetória sócio-histórica, nem as formas de subjetividade às quais se vinculam.

Ao tratar da regulação curricular da Educação Física pelo conceito de dispositivo, aqui nomeado como da esportivização da Educação Física, não se defende que o esporte de rendimento, com todas as implicações que advêm de sua prática (aspecto institucional, estrutural e organizacional, equipe de profissionais), consiga se efetivar nas aulas de Educação Física. Defende-se, por certo, que certas características do esporte de rendimento atravessam as práticas curriculares da Educação Física na escola, ao entrar nos jogos de poder-saber, que envolvem a escolha de conteúdos, metodologias, relação professor-alunos, professor-outros profissionais da escola, professor-pais. Ao entrar neste jogo, tais características disputam a hegemonia do componente curricular com outros conteúdos, outros modos de ensino, outros discursos, outras práticas, outros dispositivos.

Além disso, o dispositivo tem uma função estratégica dominante que pode se rearticular com o auxílio de suas linhas, regimes e curvas. Se algumas metas do esporte de rendimento não se mostram produtivas na Educação Física Escolar, estas podem ser revistas e substituídas por outras estratégias. É um processo sempre com vistas a efetivar algo nas práticas e discursos, mas que nunca se concretiza em sua totalidade, intensidade e plenitude, pois as disputas são intensas e o poder circula por meio de suas relações.

Portanto, a crítica na área de Educação Física sobre sua esportivização, no sentido de que a instituição esportiva adentrou a escola com todos seus princípios, códigos, objetivos e se 
efetivou nas aulas de Educação Física, difere do modo como o dispositivo aqui engendrado atua nas práticas curriculares da Educação Física. A diferença é justamente o caráter negociável atribuída às práticas escolares, bem como a (re)construção de técnicas, estratégias e metas na ação do dispositivo. Aqui, o dispositivo da esportivização se limita à escola, já que emergiu de uma investigação neste contexto e neste locus que foi analisado.

O discurso da necessidade dos professores de Educação Física em atender aos interesses dos alunos, os quais se traduzem na realização de jogos esportivos, e em especial de futebol, compôs o campo do saber e do poder do dispositivo da esportivização.

Esse discurso baliza-se pela ideia de que é preciso considerar os interesses dos alunos para que estes participem das aulas, para que se envolvam nas atividades e se mostrem comprometidos com o componente curricular. Assim, as relações de poder entre os professores e seus alunos recaem, em boa medida, na aceitação dos interesses desses últimos pelas aulas. Inclusive, em pesquisas como a de Corrêa e Moro (2004), a opinião dos alunos é o fator determinante na organização da prática curricular.

O discurso do atendimento aos interesses dos alunos nas aulas Educação Física tem-se sustentado e ainda tem força na sua definição curricular. Esse discurso, que permite o exercício do poder, funciona como uma condição de possibilidade do poder, no caso do dispositivo da esportivização, constitui-se como "[...] suporte móvel das correlações de forças que, devido a sua desigualdade, induzem continuamente estados de poder, mas sempre localizados e instáveis" (FOUCAULT, 2014, p.101).

Os professores, ao aceitarem privilegiar os esportes coletivos e principalmente o futebol numa perspectiva embasada em alguns princípios do esporte de rendimento, em detrimento de outros conteúdos e de outros modos de tratá-los, são capturados pelos saberes desse dispositivo através de suas linhas de força. Esses princípios do esporte de rendimento que atravessam as práticas curriculares da Educação Física são visibilizados, principalmente, pela prática dos jogos que são competitivos e que excluem os menos habilidosos, seja por interferência de colegas, do professor ou do próprio aluno que não se sente bem de não ter uma boa performance esportiva perante os demais. Tem-se em vista que os alunos, ao quererem o futebol ou outro esporte coletivo nas aulas de Educação Física, não querem conhecer o histórico do futebol, aprimorar o conhecimento de regras ou mesmo as técnicas e táticas esportivas, eles querem jogar!

Porém, tal captura não ocorre uniformemente, os professores trabalham com tais modalidades e alguns princípios do esporte de rendimento se fazem presentes nas aulas por meio da ação docente ou discente, sendo identificados nas práticas discursivas e não discursivas - mas decorrem de processos negociados para que o professor consiga trabalhar também de outras formas e com outros conteúdos. Os professores iniciantes negociam as práticas curriculares da Educação Física com os alunos.

No bojo dessa questão, Betti (1999) alerta que a prática de se abordar apenas, ou principalmente, os esportes nas aulas de Educação Física na escola está ligada à ideia de que o professor da disciplina é um superatleta, o que o inibe de trabalhar com práticas corporais pois não sabe executar seus movimentos básicos, de modo que os esportes são os mais conhecidos por eles: da escola à universidade. Em outros termos, essa questão remete ao discurso de que o professor de Educação Física precisa dominar a técnica das práticas 
corporais com que trabalha, transformando em conteúdo a ser ensinado aos alunos nas aulas de Educação Física.

Também não se pode ignorar que as práticas balizadas no rendimento e performances esportivas estão articuladas às concepções de Educação Física e de corpo. Este último e o movimento são aqui entendidos como os objetos de estudo e intervenção no campo da Educação Física, sendo ainda melhor definidos pelo termo cultura corporal de movimento. Neste caso, o discurso biológico do corpo, entendendo-o como um "[...] feixe de nervos, músculos e ossos que deve se locomover com o máximo de aproveitamento em um espaço pré-determinado" (BARBOSA, 2010, p.83).

Desta forma, o discurso do atendimento dos alunos em direção ao trabalho com certos conteúdos e abordagens de ensino se expressa como uma curva de enunciação do dispositivo da esportivização da Educação Física e se traduz nas categorias formais do saber: educar, tratar, punir (DELEUZE, 2005).

Os espaços físicos na escola utilizados para a realização das aulas de Educação Física também são focos de disputas. Neste caso, entre professores; um professor de Educação Física e o diretor da escola, conforme expresso nas enunciações a seguir:

O diretor é uma pessoa que se envolve muito com a questão das festas da escola, com a aparência da escola. Então, ele quer que a escola esteja sempre bonita. Lá, nós temos um ginásio muito legal [...]. Só que desde o ano passado, ele proibiu os professores de Educação Física de utilizar este ginásio. [...] cada vez ele alega que o ginásio tem um determinado problema. [...] Aí, quando tem festa na escola não tem nenhum problema. (Professora iniciante Lucíola).

O professor da manhã não gosta de dividir o pátio com ninguém. Então para não criar clima, [...] uma semana ele fica no pátio e outra semana fico eu (Professora iniciante Graziela).

No que remete às relações de força entre o professor de Educação Física iniciante (Graziela) e o professor de Educação Física mais antigo (citado por Graziela) na organização e distribuição do espaço físico para as aulas da componente curricular, evidencia-se que 0 professor iniciante tem tido pouca força em ter disponível em todas as suas aulas os locais da escola destinados para a Educação Física. As relações de poder entre esses professores se encaminham no sentido de que o primeiro faz vigorar sua preferência em desenvolver as suas aulas em um determinado espaço da escola, sem outra turma e outro professor. Esta professora iniciante aceita a vontade do professor mais antigo, o que remete para a incorporação de uma prática já estabelecida.

Uma vez que exercer o poder é agir sobre as ações dos outros, é um modo de ação de alguns sobre a ação de outros: ações sobre ações, sobre ações possíveis, atuais, futuras ou eventuais (FOUCAULT, 1995), a professora iniciante Graziela tem deixado o professor de Educação Física mais antigo exercer o poder na definição do uso do espaço físico na escola para as aulas de Educação Física. Esta prática de apenas um professor usar o espaço físico disponível para a Educação Física, no período de suas aulas, tem sido difundido nesta escola. É a condução de condutas e o ordenamento das probabilidades.

A disputa entre professor iniciante e professor mais antigo para a efetivação do discurso em questão, na ação do dispositivo da esportivização, delineia-se pelo interesse do professor mais antigo em ter, durante suas aulas, o espaço somente para si. Espaço que, 
como já discutido, dá visibilidade a um modo de ver e fazer ver a Educação Física na escola. A professora iniciante dispõe de correlação de forças para fazer de outro modo, ou seja, não se deixar conduzir pelo professor experiente. Porém, há aqui uma característica de poder institucional arraigado que sinaliza um enunciado já naturalizado que tem muita força: "quem chegou antes escolhe" ou "antiguidade é posto".

No que se refere às relações de poder entre o professor de Educação Física iniciante (Professora iniciante Lucíola) e o diretor da escola também se encaminham para a não efetivação do interesse do professor de Educação Física iniciante. Apesar da clareza e firmeza do diretor em relação ao não uso do ginásio, a professora iniciante lutou por este espaço. Foi até a Secretaria de Educação para pedir ajuda com a manutenção do ginásio, tendo em vista que os problemas detectados pelo diretor eram sempre de ordem física, técnica e não conseguiam verba e pessoal para arrumar. Essa atitude refletiu na sua avaliação como professora iniciante, já que ela encontra-se no estágio probatório.

A minha primeira avaliação foi a seguinte: que eu não conseguia resolver os problemas da escola na escola e que precisava pedir ajuda fora, por quê? Porque eu fui reclamar na SME a questão do ginásio. Então o diretor ficou sabendo [...] e me deu uma baita xingada [...]. Eu só disse para ele: 'Olha, diretor, eu estou muito tranquila em relação à minha parte, porque eu tentei resolver o problema aqui dentro, tentei conversar contigo, eu só fui lá na SME para ver se eles podiam fazer alguma coisa pela gente (Professora iniciante Lucíola).

A luta da professora em conquistar este espaço para desenvolver as suas aulas e os embates que daí resultam entre a professora iniciante e o diretor da escola traduzem as relações de poder do dispositivo da esportivização. Relações que nunca estão desconectadas de uma multiplicidade de pontos de resistência, os quais se distribuem irregularmente no tempo e no espaço, com mais ou menos densidade, como alerta Foucault. "Elas são o outro termo nas relações de poder; inscrevem-se nessas relações como o interlocutor irredutível" (FOUCAULT, 2014, p.104).

As operações de poder, para a concretização do discurso da necessidade de certos espaços físicos para a realização das aulas de Educação Física são as linhas de força agindo a serviço do dispositivo. A Professora iniciante Lucíola justifica o seu empenho para obter o ginásio da escola na seguinte direção:

\section{[...] eu acho que as minhas aulas poderiam ter muito mais qualidade se eu tivesse o meu espaço, a minha sala de aula, que é o meu ginásio que a escola tem, tendo em vista que as atividades de basquete, de quique de bola, são dificultadas. Os alunos percebem que dificulta as atividades, e eu também percebo.}

As tentativas sem êxito de obter o ginásio para o trabalho com diferentes conteúdos e outras possibilidades de ensino nas aulas de Educação Física da professora iniciante têm gerado o silenciamento de outras práticas corporais e de outros modos de tratar os conteúdos da Educação Física devido à resistência do diretor da escola. Em outras palavras, estas últimas são linhas de força agindo a serviço do dispositivo, pois reforçam e promovem um certo modo de ser da Educação Física Escolar. Uma Educação Física que é levada ao trabalho com poucas modalidades esportivas, como futebol e voleibol, com atividades que os alunos já estão acostumados a realizar, como jogos competitivos.

1 Período que o docente é avaliado pela gestão da escola de seis em seis meses, durante os primeiros três anos, e a escola deve encaminhar o resultado desta avaliação à Secretaria de Educação. 
As estratégias de poder representam o conjunto de meios para fazer agir ou manter um dispositivo de poder no comando (FOUCAULT, 1995). Elas também promovem o silenciamento de outras práticas corporais e de modos diversificados no trato de conteúdos na Educação Física, formando as linhas de força do dispositivo em questão. Nessa direção, Foucault (2014, p.110) reconhece que "[...] o silêncio e o segredo dão guarida ao poder, fixam suas interdições; mas também afrouxam seus laços e dão margem a tolerâncias mais ou menos obscuras".

Ao procurar limitar as possibilidades de conteúdo e os modos de tratá-lo na disciplina, ativam-se certas formas pelas quais se diz e se vê o componente curricular. Uma disciplina escolar que trabalha com poucos conteúdos, de modo que estes não sejam pedagogizados e imbricados com objetivos educacionais, não é valorizada na hierarquia dos saberes escolares. Até mesmo porque, nessa hierarquia, quanto mais formalizados e sistematizados, mais ligados aos saberes cognitivos e passíveis de avaliação forem estes saberes, mais valores são a eles atribuídos.

Dessa forma, tal problemática envolve o status da Educação Física como componente curricular da educação básica. Tal status é de inferioridade frente às demais disciplinas (a maioria delas), quando a preocupação é a importância do seu conhecimento para a vida escolar e para o futuro profissional dos estudantes. Os aspectos relativos ao conteúdo, à avaliação e ao próprio modo de ver a disciplina afirmam este status.

Não é oficial, mas algumas matérias eles sabem que não rodam [reprovam] e existe uma certa pressão do meio para esses alunos realmente serem aprovados nestas disciplinas [...]. Tanto as coordenadoras, quanto outros professores já falaram isso, não é realmente proibido, mas se eu rodar alunos vou arrumar animosidade com direção/coordenação e com os pais das crianças. Acontece também em artes e religião, são as disciplinas consideradas 'inúteis' pelos pais e pelos administradores. Um ou outro aluno já falou isso, que EF não roda (Professor iniciante Fabrício).

Alguns alunos não gostam de participar, parece que não roda, aí eu procuro a participação deles (Professora iniciante Patrícia).

A matéria que eu dou em aula eu faço uma provinha, com consulta, para eles não ficarem... porque senão, se eu disser para eles que eu vou dar uma prova que eles não puderem consultar, roda todo mundo, e imagina reprovar, e isso que ainda teve gente que reprovou comigo (Professora iniciante Graziela).

Uma coisa que me incomodou bastante foi a orientadora. Ela adorava ir à minha sala de aula dar ideia (ideia furada ainda), mas é porque ela ficava apontando as coisas que não tavam dando certo. E eu ficava bem louca, óbvio que eu tava vendo que não tava dando certo, mas aquilo era muito no início e eu perdia o controle dos alunos (eles muito agitados, eu muito insegura) (Professora iniciante Graziela).

Às vezes eu sinto que para a direção eu sou uma professora que fica para ocupar os alunos com alguma coisa e que eu não tenho um conteúdo a desenvolver com eles (Professora iniciante Lucíola).

O problema é com os professores que eles chamam especializados (de EF, de Artes, da Hora do Conto), professor regente não, é só os professores que entram duas vezes por semana, esses é que eles abusam e abusam (Professora iniciante Fabiana).

Em um relato de observação de pesquisa também fica claro como é tratada a Educação 
Um dia [...] a professora de Educação Física não tinha vindo. [...] Perguntei para as alunas como foi resolvida a questão. Elas disseram que a professora regente tinha entregue uma bola de futebol e os meninos foram jogar (e elas ficaram sentadas). A professora não estava junto com os alunos. Na sala dos professores ao tentar saber o que tinha acontecido, foi informado que a professora não tinha vindo porque tinha uma consulta médica e que mais detalhes poder-se-ia ter em conversa com a coordenadora (OBSERVAÇÃO 6 - 19/11/2013).

A desvalorização da Educação Física, indicando o seu baixo status frente às demais disciplinas escolares, envolve uma relação de poder a serviço do dispositivo da esportivização por estar atrelado a um modo de ver e fazer a Educação Física muito limitado ao que pode ser uma aula deste componente curricular. Está vinculado a poucos conteúdos e com alguns princípios do esporte de rendimento; à mercê do que os alunos preferem fazer; assim como os critérios de avaliação acabam sendo muito flexíveis ou inexistentes. Tais características podem ser reconhecidas como o senso comum da Educação Física Escolar, e estão presentes nas linhas de força do dispositivo, agindo a seu favor. Porém, linhas de fuga e a própria resistência, que está ligada à relação de poder, são possíveis.

Diante desta observação, realizou-se uma entrevista com a coordenadora de áreas (Educação Física, Ensino de Artes, Música) com o intuito de conversar sobre os procedimentos realizados quando algum professor não comparece à escola. Ela relata:

\footnotetext{
[...] na nossa escola a gente tenta, não mandar o aluno embora e atendê-los. Então, tipo... no currículo [anos iniciais do ensino fundamental], quando a professora titular tá aí e a professora de EF não está, a professora titular assume a turma. $\mathrm{Na}$ área [nos anos finais do ensino fundamental], o quê que a gente faz? Tenta ver outro professor que tem uma janelinha naquela aula, ou se sobe o horário das disciplinas e solta mais cedo, se não tiver a substituta. [...] Em último caso 0 aluno é mandado embora (Coordenadora das áreas).
}

As colocações desta coordenadora indicam que várias são as estratégias para resolver o problema da falta de professor, mas a questão que suscita questionamentos se refere à resposta dada por ela na sequência da entrevista, quando afirma que a aula de Educação Física é a única disciplina na escola que qualquer outro professor ou profissional assume com a ausência do professor especializado. Ela esclarece que isso ocorre porque os alunos ficam muito chateados, frustrados e revoltados se a aula de Educação Física que está prevista no horário do dia não ocorre. Além disso, a coordenadora diz que os professores ou profissionais que substituem a professora de Educação Física não dão aula desta disciplina, apenas promovem uma aula livre.

Ainda que a coordenadora justifique que o professor substituto não trabalhe com os conteúdos da Educação Física, esta flexibilidade foi construída historicamente neste campo de saber, no sentido de que a aula da disciplina ocorra, com ou sem professor especializado, de modo livre ou orientado.

A desvalorização da Educação Física, na especificidade de seus saberes, também é evidenciada nesta pesquisa. Como exemplo, destacam-se as relações de poder entre o diretor e a professora iniciante de uma das escolas, diante das restrições feitas à docente para o uso do espaço escolar nas aulas de Educação Física.

Na contramão da desvalorização da disciplina como campo de saber, a Educação Física é uma das disciplinas que os alunos mais gostam, a ponto de reclamarem quando a 
professora falta e a direção sugere a substituição da aula de Educação Física por uma aula de outra disciplina. As passagens enunciadas por professores (quando questionados sobre facilidades do trabalho com o componente), coordenadora (em entrevista) e alunos durante uma observação ilustram essa ideia:

[...] aceitação dos alunos. Eu chegar todos os dias na escola, ser a primeira professora a cumprimentarem, eles me abanarem de longe, os pequenos virem correndo da onde estão para te abraçar, sabe? Quando tem as reuniões, os conselhos de classe sempre a melhor disciplina é a EF, isso, esse é o reconhecimento que eu tenho, porque eu sei que a aula que eu levar para eles vai ser uma aula que eles vão gostar (Professora iniciante Lucíola).

Como é a Educação Física, é mais fácil trabalhar, eles gostam (Professora iniciante Patrícia).

Eu acho que a Educação Física se torna um pouco mais fácil, porque é uma coisa que eles gostam (Professor iniciante Armando).

O professor de Educação Física não veio, entra outro professor pra dar português, eles enlouquecem, entendeu? (Coordenadora das áreas).

Um aluno diz: 'A senhora tem faltado muito, sôra'. Ela diz: 'Não'. Ele diz: 'Como não, sôra? Duas semanas!' (OBSERVAÇÃO 5 - 18 nov. 2013).

Cheguei na escola, fui no pátio e tinha uma turma de alunos (meninas sentadas e meninos jogando futebol). Fui falar com as meninas. Elas disseram que a professora de Educação Física não tinha vindo. Uma aluna disse: 'Ela deu em faltar agora!' (OBSERVAÇÃO 6 - 19 nov. 2013).

Nota-se, contudo, que o elevado status da Educação Física, quando se trata dos interesses dos alunos, não segue a mesma lógica de valorização das outras disciplinas. 0 gosto pela Educação Física parece se aproximar com algo que Elias (1992) aborda na discussão do esporte: o prazer e a excitação agradável que as práticas esportivas desencadeiam em seus praticantes. Adverte-se, ainda, que os praticantes não se limitam aos jogadores, na perspectiva do autor, abrangem os espectadores e os envolvidos com os jogos.

Além disso, outros aspectos também tornam a Educação Física preferida pelos alunos: é uma disciplina que desloca os alunos da sala de aula para outro espaço físico, não tem "leitura e escrita" convencionais, há movimento do corpo.

Nessa direção, sendo o esporte o conteúdo mais trabalhado nas aulas de Educação Física, como alerta Elias (1992), o esporte é potente na promoção da excitação. Este gosto dos alunos pela aula de Educação Física pode ser um próprio efeito do dispositivo da esportivização da Educação Física. Isto ocorre porque todo dispositivo produz efeitos, subjetividades, neste caso, seriam subjetividades esportivizadas. ${ }^{2}$

Com relação aos discursos que conduzem ao trabalho apenas com esportes nas aulas de Educação Física, Barbosa (2001) se depara com alguns descritos a seguir, ao investigar as representações sociais da Educação Física Escolar, entrevistando docentes e alunos do ensino médio de uma escola do Rio de Janeiro. A maioria dos professores estudados acredita que 0 esporte deve ser o principal conteúdo trabalhado nas aulas da disciplina durante 0 período escolar. Justificam a escolha com o argumento de que durante o ensino fundamental os alunos já experienciaram todos os desportos possíveis de serem trabalhos na instituição, e, 
no ensino médio, cabe a eles escolher qual querem fazer, por prazer ou para aperfeiçoá-lo. A opinião dos alunos entrevistados segue a mesma linha, quanto ao trabalho restrito ao esporte nas escolas. Um aluno ainda anuncia que a Educação Física não tem nada a the acrescentar, porque esporte ele já pratica em uma escolinha fora da escola.

Portanto, constatou-se que as linhas de força foram evidenciadas por meio do discurso da necessidade dos professores de Educação Física em atender aos interesses dos alunos por certas modalidades esportivas, imprimindo embates entre os professores e seus alunos; pelas disputas entre professores de Educação Física de uma escola (iniciantes e experientes) e entre uma professora de Educação Física iniciante e o diretor da escola na questão do espaço físico; bem como os embates suscitados pelo status da Educação Física e seus saberes.

\section{CONCLUSÕES}

Este estudo, ao se limitar à discussão da dimensão do poder do dispositivo da esportivização da Educação Física, focalizou as estratégias definidas como ligações móveis e não localizáveis no dispositivo (DELEUZE, 2005).

As linhas de força, ao atravessarem o visível e o enunciável de qualquer dispositivo, foram evidenciadas nas próprias enunciações resultantes das entrevistas realizadas. 0 discurso da necessidade dos professores de Educação Física em atender aos interesses dos alunos por certas modalidades esportivas encadeia relações de poder, principalmente, entre professores e seus alunos. Os discentes apresentam força potente nesse jogo de poder, ainda que os docentes não aceitem, sem resistência e negociações, incorporar nas práticas curriculares da Educação Física atividades e conteúdos solicitados pelos alunos.

O uso do espaço físico também imprime relações de força no quadro curricular da Educação Física. As disputas se evidenciaram dentre professores de Educação Física de uma escola e entre o professor de Educação Física e o diretor de outra escola. A relação entre esses últimos apresentou-se peculiar, pois mesmo tendo um ginásio na escola, o diretor não autorizava a professora de Educação Física a utilizá-lo para as aulas do componente curricular. Inúmeras são as desculpas dadas para o não uso deste espaço, segundo a professora. Ela afirma que isso ocorre porque o diretor prefere manter o ginásio "em ordem" e disponível para os eventos escolares.

Essa questão remete ao status da Educação Física como componente curricular, que inclusive balizou enunciações e práticas visibilizadas na maioria das entrevistas e nas observações realizadas em uma das escolas. Esse status opera como linhas de força tanto na disputa do espaço físico quanto no desprestígio da disciplina e seus conteúdos na escola. A Educação Física é, ao mesmo tempo, uma das disciplinas menos valorizadas no currículo escolar por diretores e professores de outras disciplinas, e é a disciplina que a maioria dos alunos mais gosta de ter.

Por fim, cabe sinalizar que as relações de poder fabricam verdades que constituem todo um regime discursivo, um regime de verdade. A verdade, ao ser produzida por sistemas de poder, que também a sustentam, induz efeitos de poder, que a reproduzem. Poder e verdade estão imbricados, compõem uma dinâmica: poder produz verdade - verdade produz efeitos de poder - efeitos de poder reproduzem verdades. No entanto, esse processo não ocorre sem conflito. A ordem do discurso é da ordem da guerra: há uma luta constante por hegemonizar 
significados, verdades, discursos, enunciados, e a resistência faz parte dessa dinâmica. 0 poder precisa da liberdade para ser exercido, da possibilidade de resistência ${ }^{3}$, caso contrário seria constrangimento físico. A liberdade é condição de existência para o exercício do poder. Liberdade aqui entendida como ações que podem acontecer em um campo de possibilidades (FOUCAULT, 1995).

No locus do tema investigado, as ações que ocorrem em um campo de possibilidades podem vir a deslocar o poder, por meio das relações entre os professores de Educação Física iniciantes e outros membros da escola. Caso este poder esteja a favor do dispositivo da esportivização, haverá apenas um deslocamento de poder, mas se práticas e/ou discursos escaparem a este dispositivo, serão as linhas de fuga em ação.

\section{REFERÊNCIAS}

BARBOSA, Claudio Luis de Alvarenga. Educação Física e Didática: um diálogo possível e necessário. Petrópolis, RJ: Vozes, 2010.

BARBOSA, Claudio Luis de Alvarenga. Educação Física Escolar: as representações sociais. Rio de Janeiro: Shape, 2001.

BETTI, Irene Conceição Rangel. Esporte na escola: mas é só isso, professor? Motriz, v.1, n.1, p. 2531, 1999.

BRASIL. Conselho Nacional de Saúde. Resolução n.466, de 12 de dezembro de 2012. Disponível em: <http://bvsms.saude.gov.br/bvs/saudelegis/cns/2013/res0466 1212 2012.html>. Acesso em: 13 nov. 2014.

CORREAA, Ivan Livindo de Senna; MORO, Roque Luiz. Educação física escolar: reflexão e ação curricular. ljuí: Ed. Unijuí, 2004.

DELEUZE, Gilles. Foucault. 5. ed. Tradução de Cláudia Sant'Anna Martins. São Paulo: Brasiliense, 2005.

DELEUZE, Gilles. O que é um dispositivo? In: Michel Foucault, filósofo. Tradução de Wanderson Flor do Nascimento. Barcelona: Gedisa, 1990. p. 155-161.

ELIAS, Norbert. A génese do desporto: um problema sociológico. In: ELIAS, Norbert; DUNNING, Eric. A busca da excitação. Lisboa: DIFEL, 1992. p.187-219.

FOUCAULT, Michel. História da sexualidade 1: A vontade de saber. São Paulo: Paz e Terra, 2014.

FOUCAULT, Michel. O sujeito e o poder. In: DREYFUS, Hubert; RABINOW, Paul. Michel Foucault: uma trajetória filosófica: para Além do Estruturalismo e da Hermenêutica. Rio de Janeiro: Forense Universitária, 1995. p. 231-249.

FOUCAULT, Michel. Microfísica do poder. Rio de Janeiro: Graal, 1992.

ILHA, Franciele Roos da Silva. A regulação curricular da Educação Física na escola e seus efeitos no trabalho de professores iniciantes. 2015. 197f. Tese (Doutorado) - Universidade Federal de Pelotas, Pelotas, 2015.

3 A discussão da resistência e das linhas de fuga foi timidamente abordada para não ultrapassar o número máximo de caracteres da revista. Esta discussão é encontrada na íntegra em llha (2015). 
NEIRA, Marcos Garcia; NUNES, Mário Luiz Ferrari. Educação Física, currículo e cultura. São Paulo: Phorte, 2009.

SILVEIRA, Rosa Maria Hessel. A entrevista na pesquisa em educação: uma arena de significados. In: COSTA, Marisa Vorraber (Org.). Caminhos investigativos II: outros modos de pensar e fazer pesquisa em educação. 2. ed . Rio de Janeiro: Lamparina 2007. p.117-138. 


\section{Apoio financeiro:}

Conselho Nacional de Pesquisa e Desenvolvimento Científico e Tecnológico (CNPQ) e Coordenação de Aperfeiçoamento de Pessoal de Nível Superior (Capes). 